\title{
Uranium Liquid-Argon Calorimeters: A Calculational Investigation
}

\author{
T. A. Gabriel
}

\section{OAK RIDGE NATIONAL LABORATORY}

OPERATED BY UNION CARBIDE CORPORATION FOR THE ENERGY RESEARCH AND DEVELOPMENT ADMINISTRATION 


\section{DISCLAIMER}

This report was prepared as an account of work sponsored by an agency of the United States Government. Neither the United States Government nor any agency Thereof, nor any of their employees, makes any warranty, express or implied, or assumes any legal liability or responsibility for the accuracy, completeness, or usefulness of any information, apparatus, product, or process disclosed, or represents that its use would not infringe privately owned rights. Reference herein to any specific commercial product, process, or service by trade name, trademark, manufacturer, or otherwise does not necessarily constitute or imply its endorsement, recommendation, or favoring by the United States Government or any agency thereof. The views and opinions of authors expressed herein do not necessarily state or reflect those of the United States Government or any agency thereof. 


\section{DISCLAIMER}

Portions of this document may be illegible in electronic image products. Images are produced from the best available original document. 


\section{Printed in the United States of America. Available from National Technical Information Service \\ U.S. Department of Commerce 5285 Port Royal Road, Springfield, Virginia 22161 \\ Price: Printed Copy $\$ 4.00$; Microfiche $\$ 3.00$}

This report was prepared as an account of work sponsored by the United States Government. Neither the United States nor the Energy Research and Development Administration/United States Nuclear Regulatory Commission, nor any of their employees, nor any of their contractors, subcontractors, or their employees, makes any warranty, express or implied, or assumes any legal liability or responsibility for the accuracy, completeness or usefulness of any information, apparatus, product or process disclosed, or represents that its use would not infringe privately owned rights. 
Contract No. W-7405-eng-26

Neutron Physics Division

Uranium Liquid-Argon Calorimeters:

A Calculational Investigation*

\author{
T. A. Gabriel
}

Date Published - June 1977

* Submitted for

Journal Publication

NOTICE This document contains information of a preliminary nature. It is subject to revision or correction and therefore does not represent a final report.

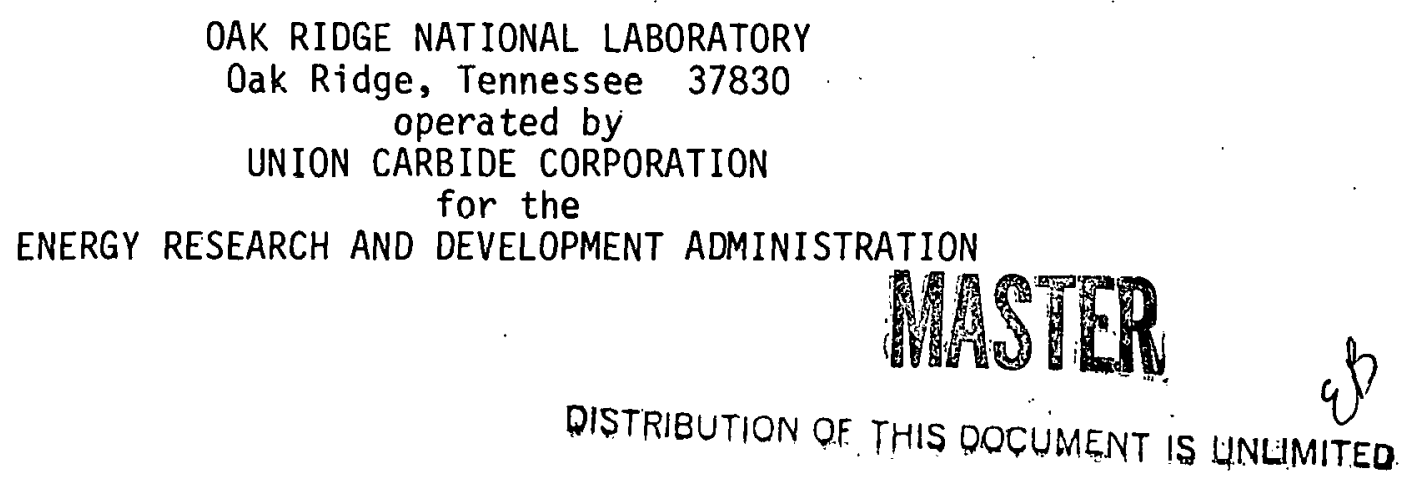


THIS PAGE

WAS INTENTIONALLY

LEFT BLANK 


\section{ACKNOWLEDGEMENTS}

The author wishes to thank Dr. Chris Fabjan and Dr. Bill Willis

of CERN, Dr. Walter Selove of the University of Pennsylvania, and

Dr. R. G. Alsmiller, Jr. and Dr. H.W. Bertini of Oak Ridge

National Laboratory for many helpful and interesting discussions during the course of this work. 
THIS PAGE

WAS INTENTIONALLY

LEFT BLANK 


\title{
Table of Contents
}

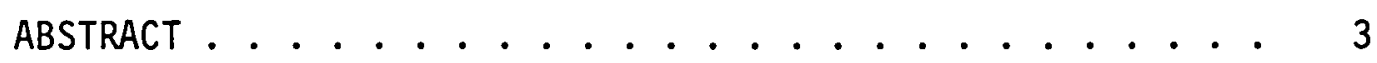

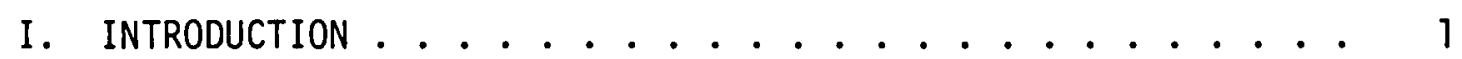

II. DESCRIPTION OF CALORIMETER AND CALCULATIONAL PROCEDURES . • 2

III. RESULTS ............................... 4

A. Pure Uranium Case ............... 4

B. Iron-Argon Calorimeter Results .......... 8

C. Uranium-Iron-Argon and Uranium-Argon Calorimeter Results 11
\end{abstract}

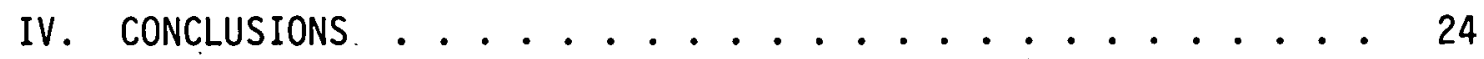


THIS PAGE

WAS INTENTIONALLY

LEFT BLANK 


\section{URANIUM LIQUID-ARGON CALORIMETERS: \\ A CALCULATIONAL INVESTIGATION}

T. A. Gabriel

\section{ABSTRACT}

A detailed calculational study has been performed to determine the response of uranium liquid-argon calorimeters to high energy ( $\leq 20 \mathrm{GeV}$ ) incident protons. The results obtained are consistent with the recently published experimental data of Fabjan et al. This experimental data and the calculations indicate that "nuclear fluctuations", which limit the resolution of calorimeters containing ordinary materials, can be effectively reduced by the fissioning and capture characteristics of $238 \mathrm{U}$. 


\section{Introduction}

Due to the fissioning and capture characteristics of natural uranium, "nuclear fluctuations" which usually dominate the resolution in total absorption calorimeters containing ordinary materials can be reduced substantially.1,2 This reduction can be explained in the following way. If the particle cascade generated in the calorimeter is strongly electromagnetic through the production of $\pi^{\circ} \mathrm{s}$, etc., there will be only a slight amplification of the signal due to the small photofission cross section and due to the reasonably small number of secondary hadronic particles, especially neutrons. For a fixed incident energy, the signal received from largely electromagnetic cascades normally represent the upper part of the pulse height distribution, i.e., the larger signals. However, if the particle cascade is strongly hadronic, there will be a reasonably large amplification of the signal due to hadronic induced fission and neutron capture. Without the amplification the signal would normally represent the lower part of the pulse height distribution, i.e., the smaller signals. Since the normally smaller signal receives the greater amplification, this leads to a narrowing of the pulse height distribution as well as an increase in the value of the most probable pulse. Both of these effects reduce the resolution. It should be noted that most of the fission energy, $\sim 170 \mathrm{MeV} /$ fission, results from heavy fragment recoil. This energy is deposited within the uranium and therefore is not detectable. It is the fission neutrons and gammas which are of interest and that can be detected.

In this paper, calculations are presented in which fission amplification of calorimeter stgnals are investigated. The desiyn of the 
calorimeter chosen for consideration is similar to that employed in Ref. 1. This will allow some comparisons with experimental data. It will be shown that it is possible calculationally to predict with reasonable accuracy the performance of uranium-loaded calorimeters. Presented in Section II is the geometry of the calorimeter and the methods of calculation, and, in Section III, the results are presented and discussed.

\section{Description of Calorlmeter and Calculational Procedures}

The geometry and materials of the calorimeter are given in Fig. 1 . In most of the calculations this was the arrangement. For some calculations the uranium was replaced by iron making the device totally iron and liquid argon. Also for some calculations the iron was replaced by uranium making the device totally uranium and liquid argon. In all cases, the radii, dead spots, gaps, plates, etc. all remained the same dimensional size as given in Fig. 1. The naturally occurring isotopic composition of $U, F e$ and $A$ was used.

Except for the more detailed treatment of the low-energy ( $E \leq 20 \mathrm{MeV}$ ) neutrons and excitation gammas, and the inclusion of high energy ( $E>0$ for protons, $\pi^{ \pm}$, and $E \geq 20 \mathrm{MeV}$ for neutrons) particle-induced fission, the calculations are the same as those described in Ref. 3 . The fission r.ross sections used in the calculation for high-energy particleinduced fission were taken from Ref. 4. (See p. 666, Fig. 7, $Z_{f}=90$. ) The lowest energy point where a fission cross section was given was ح $100 \mathrm{MeV}$. Below this energy to $20 \mathrm{MeV}$, the fission data needed was obtained by linear extrapolation using the $20-\mathrm{MeV}$ neutron fission cross section obtained from ENDFB $/ 4^{5 / /}$ to define the lower energy point. These 
ORNL-DWG 77-2981R

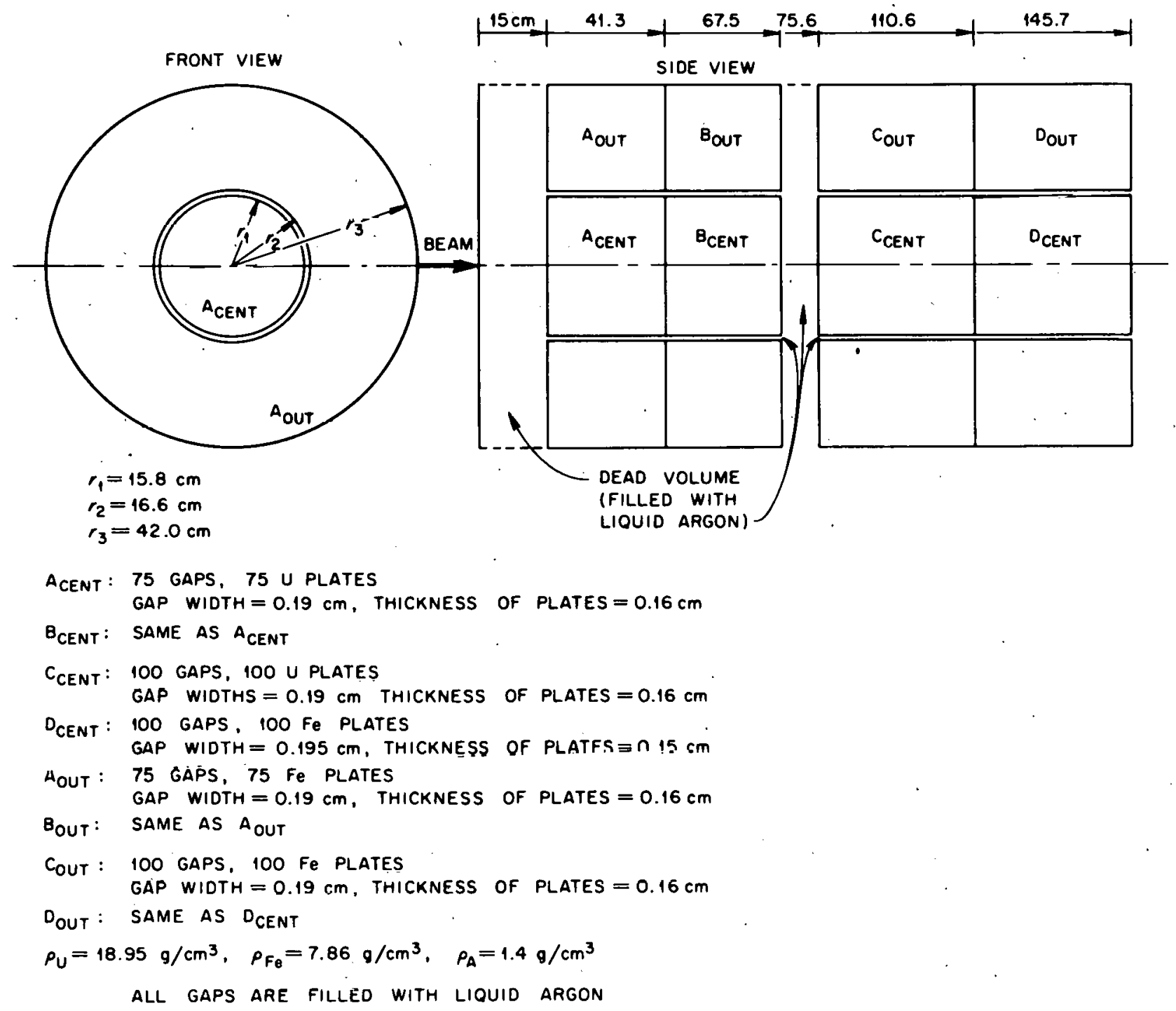

Fig. 1. Geometry and Composition of the Calorimeter. 
fission cross sections were assumed to apply for neutrons, protons, and charged pions. For the charged pions, the energy used for the cross section determination was the total energy. One nice feature of the high energy particle collision mode $1^{6 / /}$ used in the calculation is that the neutron multiplicities associated with high energy fission are automatically taken into account without any additions to the model. (See p. 667, Fig. 8 of Ref. 4) Fission gammas from the high-energy particle-induced fissions were assumed to have the same spectral distribution ${ }^{5}$ as those from low-energy neutron-induced fissions. These fission gammas, as well as neutrons below $20 \mathrm{MeV}$ and deexcitation gammas were transported using a modified version of M(RSE $\left.{ }^{a}\right) 7 / / /$. The neutronand gamma-cross sections used by MøRSE were obtained from ENDFB/4 $5 / / /$ and were processed using $A M P X^{8 / / /}$.

\section{Results}

A. Pure Uranium Case

Results are presented in Fig. 2 of an idealized casc in which protons of various energies are incident on an infinite natural uranium system. No particle leakage has been allowed. Fig. 2a indicates that $\sim 24$ fissions/ $/ \mathrm{GeV}$ of proton energy res $\mu 1$ ts (5 from ${ }^{235 \mathrm{U}}$, and 19 from $238 \mathrm{U})$. Of these, 19 fissions $/ 1 \mathrm{GeV}$ of proton energy results frum neutrons with energy $\leq 20 \mathrm{MeV}(5$ from $235 \mathrm{U}$, and 14 from $230 \mathrm{U}$ ). The number of captures that occur are given in Fig. 2b. Approximately 82 captures $/ 1 \mathrm{GeV}$ of proton energy results. The majority $(\sim 99 \%)$ of the

\footnotetext{
${ }^{a}$ The main modification of the MØRSE code was to explicitly account for Compton, pair production and photoabsorption-type processes associated with the transport of the gammas. The electrons produced were transported using the straight ahead approximation and the associated stopping power formula.
} 


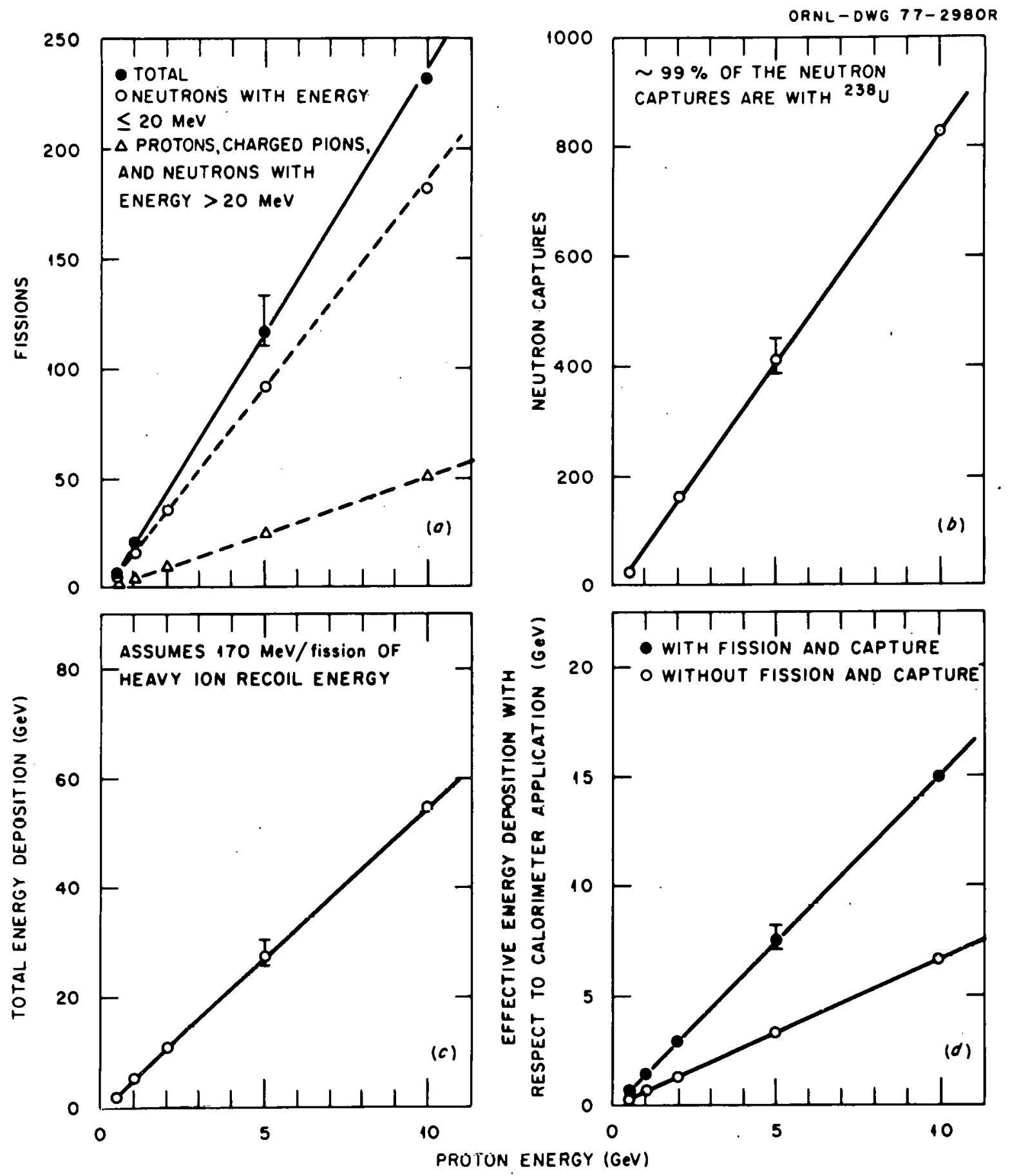

Fig. 2. Fissions, Captures, Energy Deposition and Effective Energy Deposition in an Infinite Uranium System Produced by Protons of Various Energies. 
captures occur. with $238 U$. Fig. 2c shows the total energy deposition. This yield amounts to $\sim 5.4 \mathrm{GeV} / 1 \mathrm{GeV}$ of incident proton energy. However, for calorimeter applications the majority of the energy ( $170 \mathrm{MeV} / \mathrm{fission}$ ) is not available for detection. The energy that is available for detection is shown in Fig. 2d (upper curve). The lower curve in this figure indicates the available energy if fission and capture are omitted. As can be seen, there is a substantial increase in the "effective energy" due to fission and capture. The "error bars" for the 5-GeV energy case given in the figure represent upper and lower bounds of uncertainty associated with the calculational model. They are not error bars for statistical fluctuations associated with the calculations. Similar uncertainties can be applied to the other energies.

Shown in Fig. 3 is the time scale associated with fission, capture, energy deposition and effective energy deposition for 5-GeV incident protons. Since the high energy transport code ${ }^{9}$ and the electron-photon transport code 10 do not have a timing scheme incorporated, it has been assumed that no time has passed for this phase of the particlc cascade. Therefore, all energy deposited from this phase of the calculation is deposited at $t=0$ and all low-energy ( $E \leq 20 \mathrm{MeV}$ ) neutrons, high-energy partic.le-produced fission gamma-rays, and deexcitation gamma-rays are born at time $=0$. In actuality, these particles are usually born and the energy deposited in a time window from 0 to $u 30$ isec. Thereforn, the time scale shown must be considered an absolute lower limit for the processes indicated. Although these curves are for a total uranium system, they should be approximately applicable for calorimeter systems in which there is negligible leakage since the uranium will constitute 


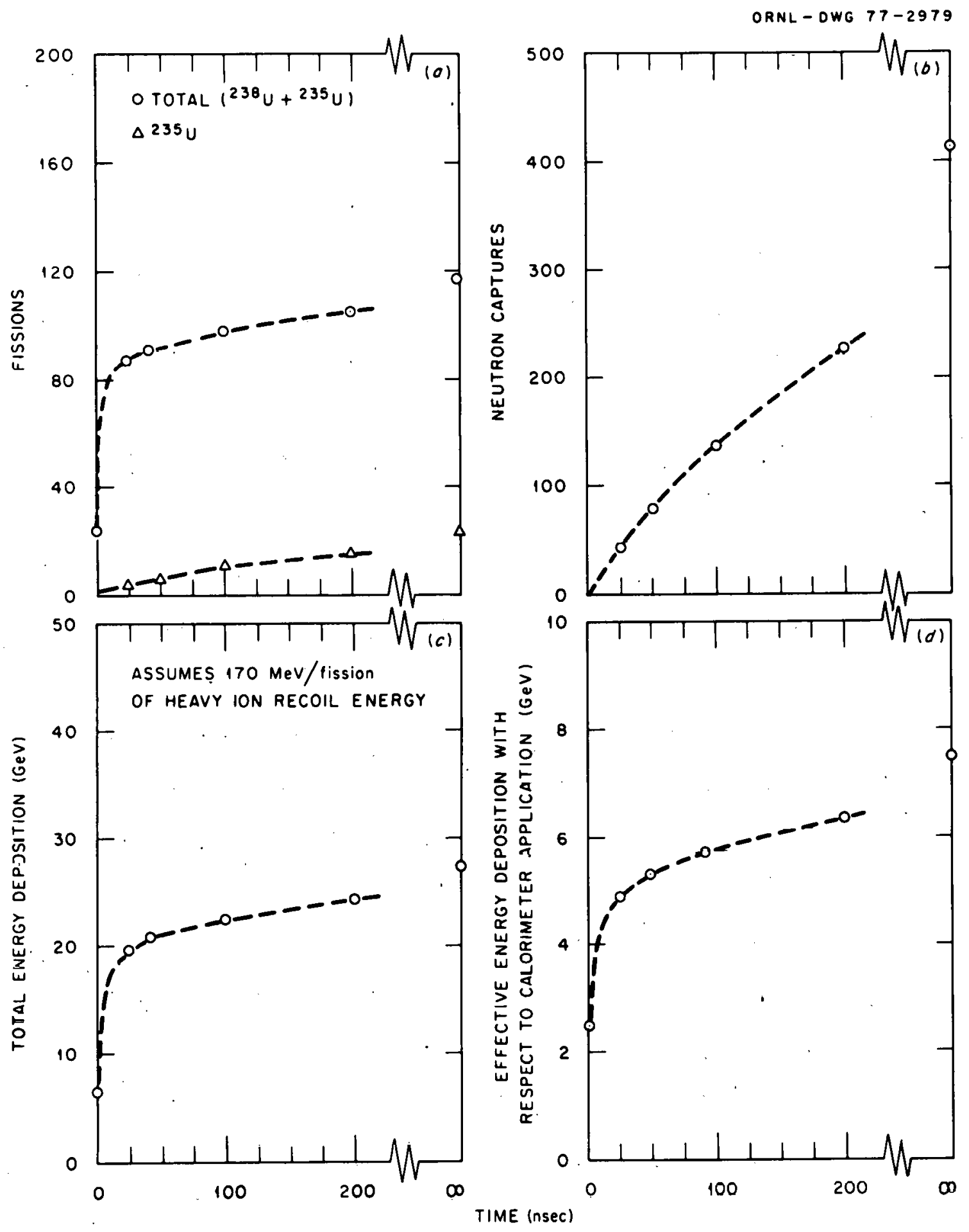

Fig. 3. Fissions, Captures, Energy Deposition and Effective Energy Deposition in an Infinite Uranium System as a Function of Time for Incident 5-GeV Protons. 
a large fraction of the total mass in calorimeters. As can be seen, a substantial amount of time is required before the entire "effective" energy is deposited: This may present a possible problem due to pileup for a large nonleaking calorimeter system if they are to be used in a beam which has a high current $\left(\sim>10^{6}\right.$ particles $\left./ \mathrm{sec}\right)$ or when two particles enter the device with a $\Delta t$ of $<1 \times 10^{-6} \mathrm{sec}$.

B. Iron-Argon Calorimeter Results

$$
\text { Since a detailed treatment of the low-energy ( } E \lesssim 20-M e V \text { ) }
$$

neutrons and excitation gamma rays had not been included in obtaining previous calorimeter results, a calculation was carried out for a total iron-argon (Fe-A) system for incident 5-GeV protons. The purpose of this calculation is two-fold. First, this calculation will partly validate the more detailed treatment of the low-energy neutrons and excitation gamma rays and will also given an indication of the magnitude of any nonlinear effects (i.e., the charge collected is not linearly related to the energy deposited) associated with heavily ionizing particles. ${ }^{11}$ The results of the calculation are given in Fiy. 4 and Table 1. As can be seen in Table 1, the approximation used in previous calculations to determine the energy deposition of low-energy neutrons and deexcitation gamma rays is quite good. The sampling fluctuation distribution was obtained by taking the difference in the signal obtained from alternating pairs of argon gaps for each incident particle; i.e., gap $_{1}+\mathrm{gap}_{2}-\mathrm{gap}_{3}-\mathrm{gap}_{4}+\mathrm{gap}_{5}+\mathrm{gap}_{6}-\mathrm{gap}_{7}-\mathrm{gap}_{8}+$ etc. $=I_{1}-I_{2}$. Both the resolution and the sampling fluctuation are in excellent agreement with experimental data ${ }^{1}$. 


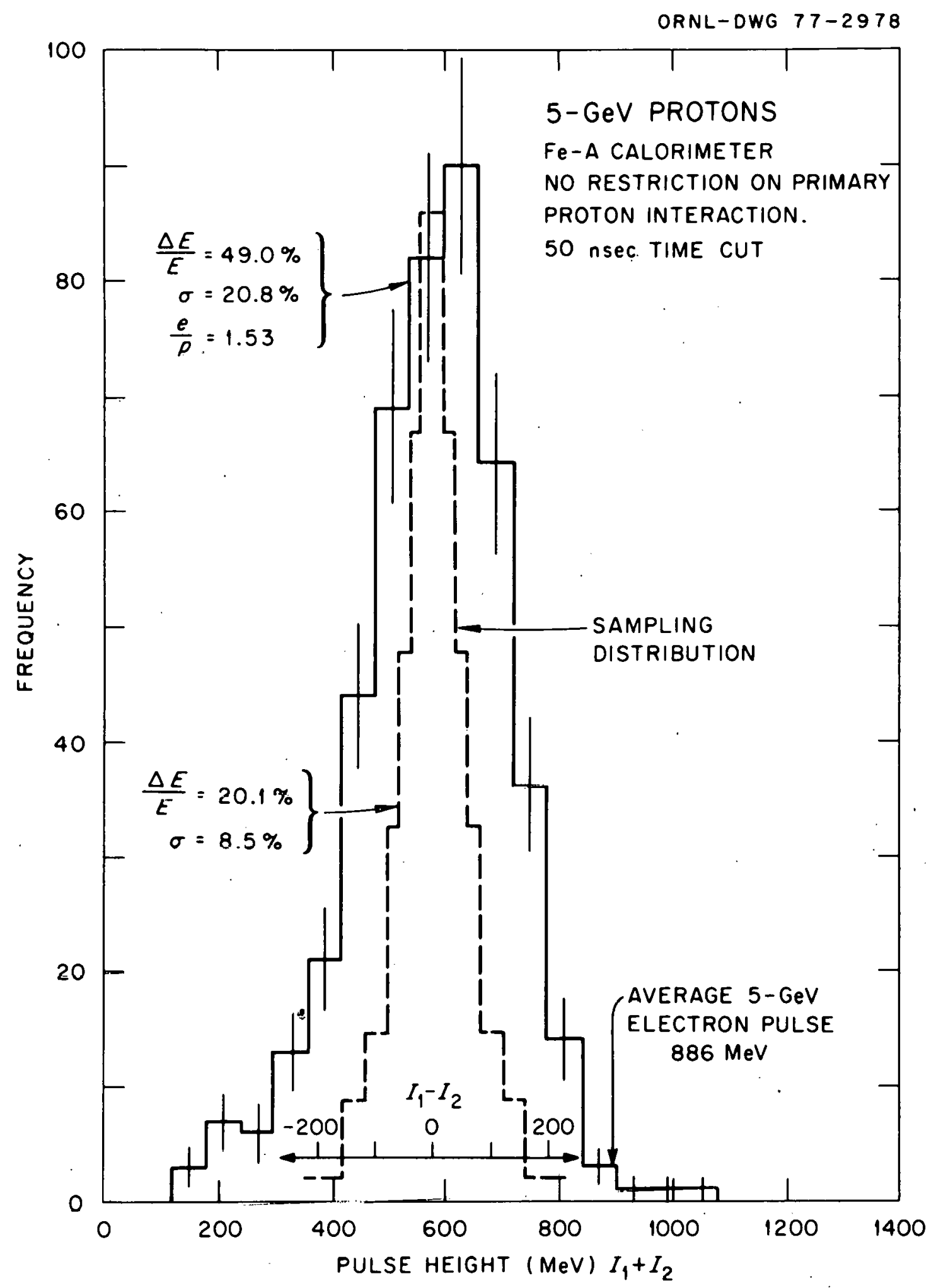

Fig. 4. Pulse Height and Sampling Distributions Expected from an Iron-Argon Calorimeter When 5-GeV Protons are Incident: 
Table 1

Energy Deposition and Leakage Produced by the Interaction of $5-\mathrm{GeV}$ Protons in an Iron-Argon Calorimeter ${ }^{a}$

\section{Energy Deposition ${ }^{\mathrm{b}}(\mathrm{MeV})$}

1. Primary ionization

2. Secondary proton ionization

3. Secondary $\pi^{ \pm}$ionization

4. Secondary $\mu^{ \pm}$ionization

5. Nuclear-recoil and evaporatedcharged particles other than protons produced by $p$ and $\pi^{ \pm}$and neutrons with $\mathrm{E}>20 \mathrm{MeV}$

6. Neutrons with energy $<20 \mathrm{MeV}$ and deexcitation gamma-rays

7. Electromagnetic from $\pi^{\circ}$ decay
Iron plus Argon 187. 1424 . 362 . $8 . y$

112.

298.

817.

3209 .
Active Argon

27.1

234 .

60.7

1.5

19.6

$88.8(75.4)^{\mathrm{e}}$

145.

Total 3209 . 577.

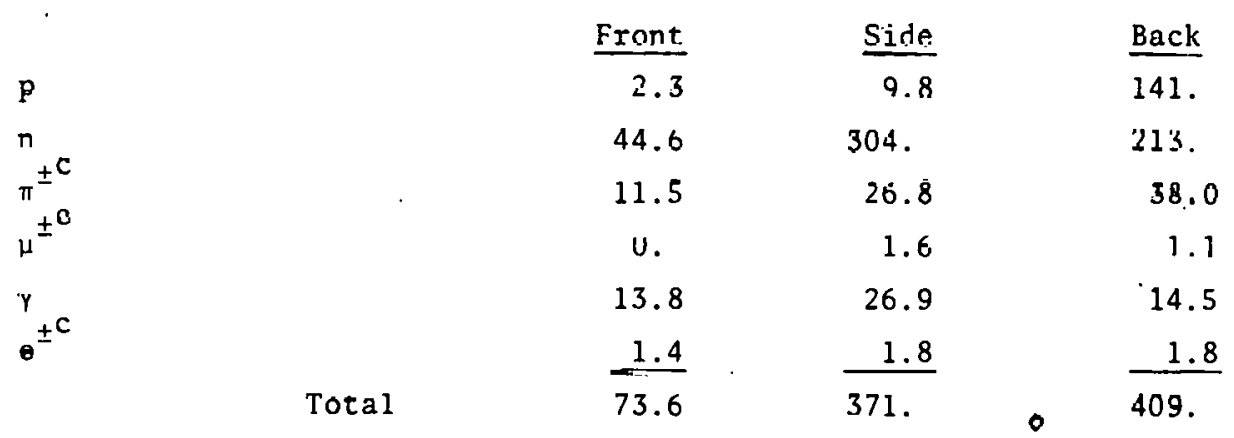

Total leakagè energy $=854 . \mathrm{MeV}$ Binding plus $v$ energy $=937 . \mathrm{MeV}$ Electromagnotir snurse energy $\left(\pi^{\circ}\right)=854 . \mathrm{MeV}$

${ }^{a}$ See description of calorimeter

b50 nsec time cut

cIncludes rest mass

dincludes some energy lost due to b)

eValue obtained by prorating neutron and gamma-ray source energy on a gm thickness basis 
If the initial interaction of the incident proton is restricted so that the amount of leakage energy is reduced the $e / p$ ratio decreases to 1.40. The experimental value obtained under similar conditions is $1.52^{1}$. This implies an $8 \%$ nonlinear effect if it is assumed that there are no other contributing factors. This $8 \%$ nonlinear effect for argon devices is approximately $1 / 2$ that which is expected for plastic or liquid scintillators. ${ }^{3}$ Average pulses were used to calculate the e/p ratio. If the most probable proton pulse had been used the nonlinear effect would have been larger. Therefore, the $8 \%$ will be taken to represent a lower estimate for $5-\mathrm{GeV}$ protons incident on the Fe-A calorimeter.

Increasing the cascade transport time upwards from $50 \mathrm{nsec}$ does not yield a much larger signal. In the calculations given here no time has been allowed for the drift time of the electrons across the argon gaps.

C. Uranium-Iron-Argon and Uranium-Argon Calorimeter Results The number of $238 \mathrm{U}$ fissions that can be expected in a realistic calorimeter are given in Fig. 5 as a function of incident proton energy. Even for the uranium=aryun (U-A) results, the number of fissions are substantially less than the number obtained for the infinite uranium system. This decrease is due to leakage energy and energy loss in the iron and/or argon.

The energy deposition and leakage summary sheets for the proton energies considered are given in Tables 2 and 3 for the uranium-iron-argon (U-Fe-A) calorimeter, and Table 4 for the U-A calorimeter. To obtain the energy deposition for the entire system, the heavy ion recoil energy associated with fission has been taken to be $170 \mathrm{MeV}$. Even for this relatively large device the energy leakage is $\sim 15 \%$. 


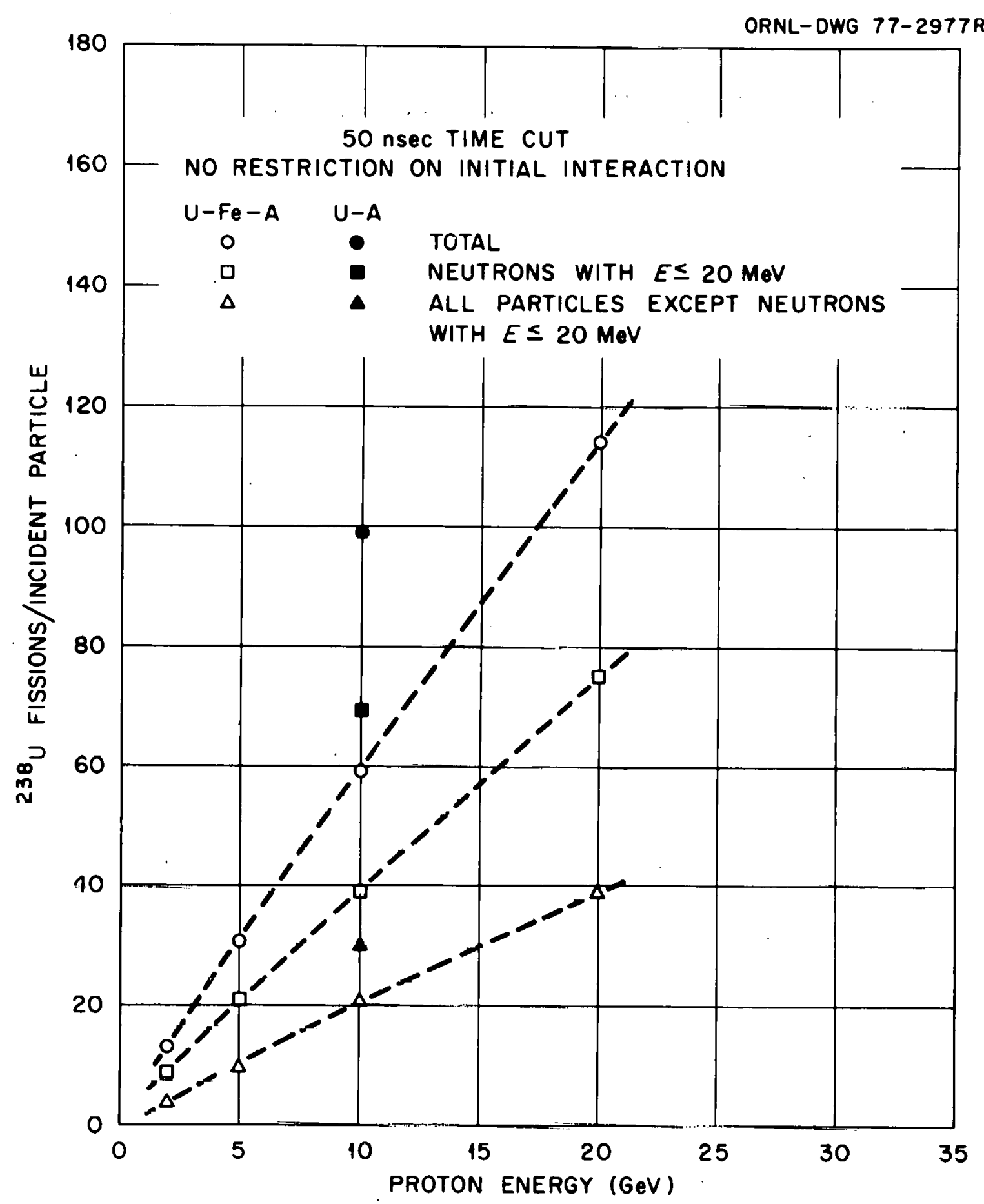

Fig. 5. Number of $238 \mathrm{U}$ Fissions Expected in a U-Fe-A and a U-A Calorimeter as a Functiuri of Proton Energy. 
Table 2

Energy Deposition and Leakage Produced by the Interaction of

2- and 5-GeV Protons in a Uranium-Iron-Argon Calorimeter ${ }^{\mathrm{a}} \mathrm{e}$

2-GeV Protons

Energy Deposition ${ }^{b}(\mathrm{MeV})$

Entire System Active Argon

1. Primary ionization

2. Secondary proton ionization

3. Secondary $\pi^{ \pm}$ionization

4. Secondary $\mu^{ \pm}$ionization

5. Nuclear-recoil and evaporated-charged particles other than protons produced by $p$ and $\pi \pm$ and neutrons with $\mathrm{E}>20 \mathrm{MeV}$

6. Neutrons with energy $<20 \mathrm{MeV}$, deexcitation gamma-rays, and fission

7. Electromagnetic from $\pi^{\circ}$ decay Total

\section{p}

n

$\pi^{+c}$

$\mu^{ \pm C}$

$\gamma$

$\mathrm{e}^{ \pm c}$
215.

530.

82.2

1.9

65.7

4.6

$$
2748 .(265 .)^{d}
$$

138 .

$\overline{3781 .(1298 .)^{d}}$

$\frac{13.0}{165 .(135 .)^{d}}$
20.1

60.5

8.8

0.23
Leakage Energy ${ }^{\mathrm{b}}(\mathrm{MeV})$

(with fission, capture, etc.)
Front

0.70

31.4

4.1

0 .

6.4

Total $\frac{1.3}{44.2}$
Side

3.9

121.

2.5

0.28

5.7

$0.17^{\circ}$
Number of fissions/incident particle $=12.9$

Total leakage energy $=203$. MeV

Electromagnetic source energy $\left(\pi^{\circ}\right)=145 \mathrm{MeV}$ 
Table 2 (Cont'd)

5-GeV Protons

Energy Deposition ${ }^{\mathrm{b}}(\mathrm{MeV})$

1. Primary ionization

2. Secondary proton ionization

3. Secondary $\pi^{ \pm}$ionization

4. Secondary $\mu^{ \pm}$ionization

5. Nuclear-rernil and evaporated-charged particles other thal pruluns producod by $\mathrm{p}$ and $\pi^{ \pm}$and neutrons with $\mathrm{E}>20 \mathrm{MeV}$

6. Neutrons with energy $<20 \mathrm{MeV}$, deexcitation gamma-rays, and fission

7. Electromagnetic from $\pi^{\sim}$ decay

$$
\text { Total } \overline{125} \text {. }
$$

\section{Total}$$
\text { lotal }
$$$$
\text { Leakage Energy }{ }^{\mathrm{b}} \text { (MeV) }
$$$$
\text { (with fission, capture, etc.) }
$$$$
\begin{array}{r}
\text { Front } \\
\hline 5.1 \\
90.4 \\
11.0 \\
0.1 \\
12.9 \\
\frac{2.0}{125 .}
\end{array}
$$$$
\text { Side }
$$$$
7.3
$$$$
273 \text {, }
$$$$
7.5
$$$$
0.3
$$$$
10.8
$$$$
0.9
$$$$
12.4
$$

$$
20.7
$$$$
149 .
$$$$
34.5
$$$$
0.6
$$

4.6

0.6

175.

12.4

$6541 .(641 .)^{d}$

$141 .(67.0)^{\mathrm{d}}$

637.

$\overline{9125 .(3225 .)^{d}}$

$\frac{6 ? .8}{121 .(347 .)^{d}}$

300.

Back

53.9

65.9

8.5

0 .

2.2

Number of fissions/incident particle $=30.5$

Tutal leakage energy $=557 . \mathrm{MeV}$

Hlectrömagnctic sourse energy $\left(\pi^{\circ}\right)=655$. MeV

${ }^{a}$ See description of calorimeter

b50 nsec time cut

$c^{\text {Includes rest mass }}$

dWithout fission and capture

$e_{\text {No }}$ restriction on initial interaction 
Table 3

Energy Deposition and Leakage Produced by the Interaction of 10- and 20-GeV Protons in a Uranium-Iron-Argon Calorimeter

10-GeV Protons

$$
\text { Energy Deposition }{ }^{b}
$$

$(\mathrm{MeV})$

\section{Entire System}

242.

2472 .

671.

5.5

295.

particles other than protons produced by $p$ and $\pi^{ \pm}$and neutrons with $E>20 \mathrm{MeV}$

6. Neutrons with energy $<20 \mathrm{MeV}$, deexcitation gamma-rays, and fission

7. Electromagnetic from $\pi^{\circ}$ decay

$$
\begin{aligned}
& \text { Total } \\
& \text { Leakage Energy }{ }^{b} \text { (MeV) } \\
& \text { (with fission, capture, etc.) } \\
& \begin{array}{ccc}
\text { Front } & \text { Side } & \text { Back } \\
16.6 & 17.5 & 89.5 \\
225 . & 515 . & 198 .
\end{array}
\end{aligned}
$$

$\mathrm{n}$

$\pi^{ \pm C}$

$\mu^{ \pm C}$

$\mathrm{e}^{\mathrm{Y}} \mathrm{c}$

$\begin{array}{ll}12637 .(1198 .)^{\mathrm{d}} & 271 .(127 .)^{\mathrm{d}} \\ \frac{1483 .}{17806 .(6367)^{\mathrm{d}}} & \frac{148 .}{853 .(709)^{\mathrm{d}}}\end{array}$

1.3

32.5

Active Argon

21.9

304 .

75 .

0.69 
Table 3 (Cont'd)

20-GeV Protons

Energy Deposition ${ }^{\mathrm{b}}(\mathrm{MeV})$

1. Primary ionization

Entire System Active Argon

2. Secondary proton ionization

275 .

25.5

3. 3ecundary $\pi^{ \pm}$ionization

4702 .

583.

4. Secondary $\mu^{ \pm}$ionization

1325 .

147.

5: Nuglear-rernil and evaporated-charged particles other than protons produced by $\mathrm{p}$ and $\pi^{ \pm}$and neutrons with $\mathrm{E}>20 \mathrm{MeV}$

16.8

2.3

6. Neutrons with energy $<20 \mathrm{MeV}$, deexcitation gamma-rays, and fission

537.

49.9

7. F.lectromagnetic from $\pi^{\circ}$ decay

$24247 .(2283 .)^{d}$

518. (243.)

Total $\frac{3686 .}{34789 .(12825)^{d}} \frac{372 .}{1698 .(1423 .)}$

Leakage Energy ${ }^{b}(\mathrm{MeV})$

(with fission, capture, etc.)

$\mathrm{p}$

n

$\pi^{+1} \mathrm{C}$

$u^{ \pm}$

'r'

$e^{ \pm^{c}}$

\begin{tabular}{|c|c|c|c|}
\hline & Front & Side & Back \\
\hline & 30.3 & 15.7 & 230. \\
\hline & 448 & 869 & 595 \\
\hline & 217 & 11.1 & 139. \\
\hline & 0 & 0 & 7.0 \\
\hline & . 27.5 & 34.5 & 9.6 \\
\hline & 6.7 & 2.0 & 13.1 \\
\hline Total & 750 & 932. & yy4. \\
\hline
\end{tabular}

${ }^{a}$ See description of calorimeter

$\mathrm{b}_{50}$ nsec time cut

Includes rest mass

$\mathrm{d}_{\text {Wjthout fission and capture }}$

$\mathrm{e}_{\mathrm{N}}$ restriction on initial interaction 
Table 4

Energy Deposition and Leakage Produced by the Interaction of $10-\mathrm{GeV}$ Protons in a Uranium-Argon Calorimeter ${ }^{a}, d$

\section{Energy Deposition ${ }^{\mathrm{b}}(\mathrm{MeV})$}

\section{Entire System}

260.

2405 .

668.

10 .

4. Secondary $\mu^{ \pm}$ionization

5. Nuclear-recoil and evaporated-charged particles other than protons produced by $p$ and $\pi^{ \pm}$and neutrons with $E>20 \mathrm{MeV}$

6. Neutrons with energy $<20 \mathrm{MeV}$, deexcitation gamma-rays, and fission

7. Electromagnetic from $\pi^{\circ}$ decay

$$
\text { Total }
$$

Leakage Energy ${ }^{\mathrm{b}}(\mathrm{MeV})$

(with fission, capture, etc.)

$\begin{array}{lccc} & \frac{\text { Front }}{12.5} & \frac{\text { Side }}{5.0} & \frac{\text { Back }}{116 .} \\ \mathrm{p} & 210 . & 385 . & 155 . \\ \mathrm{n}{ }^{ \pm \mathrm{C}} & 53.0 & 4.6 & 23.1 \\ \pi^{ \pm} & 0 . & 0.7 & 0 . \\ \mu^{ \pm} & 41.6 & 10.2 & 5.8 \\ { }^{ \pm}{ }^{ \pm} \mathrm{C} & \frac{5.8}{323 .} & \frac{0.8}{406 .} & \frac{1.5}{301 .}\end{array}$

Number of fissions/incident particle $=99.0$

Tntal leakage energy $=1030 . \mathrm{MeV}$

Electromagnetic source energy $\left(\pi^{\circ}\right)=1509 . \mathrm{MeV}$

${ }^{a}$ See description of calorimeter

$b_{50}$ nscc time cul

cIncludes rest mass

$d_{\text {No }}$ restriction on initial interaction 
For the $10-\mathrm{GeV} U-\mathrm{Fe}-\mathrm{A}$ and $\mathrm{U}-\mathrm{A}$ cases, calculations were also done in which no time cutoff was imposed. The resulting energy deposition in the active argon increased from $853 \mathrm{MeV}$ to $878 \mathrm{MeV}$, and $861 \mathrm{MeV}$ to $941 \mathrm{MeV}$, respectively. Note that for the U-A calorimeter, the signal increase is larger ( $9 \%$ compared to $3 \%$ ) and would require a longer collection time.

The pulse height distributions with and without fission, etc., and the sampling distributions are given in Figs. 6,7 , and $8 . *$ The narrowing of the pulse height distributions as well as the shift in the location of the most probable pulse are quite apparent due to the amplification of the signal due to fissioning and capture.

The resolution of the U-Fe-A calorimeter as a function of proton energy is given in Fig. 9a. Since a large part of the nuclear fluctuations have been removed due to the use of uranium, the sampling fluctuation now represents a larger fraction of the total resolution. By quadratically subtracting the sampling fluctuations, the intrinsic resolution of the device can be ublained. Thr remaining flurtuations for this device are attributed to leakage and fluctuations in the fission and rapture processes. In Fig. $9 b$ the results of the resolution and sampling fluctuation calculations are compared to the date given in Ref. 1. The agreement is quite qood.

The ratio of the average electrunic energy drposition to the average hadronic energy deposition is given in Fig. 10 as a function of particle energy and as a function of several different constraints. For the cases in which no restriction has been applied to the initial interaction the $e / p$ ratio decreases at first, but then starts to increase again.

${ }^{\star} \sigma^{\star}$ shown in the Figs. is the resolution with the sampling fluctuations subtracted. 
$U-F e-A$ CALORIMETER

VO RESTRICTIONS ON INITIAL INTERACTION 50 nsec TIME CUT
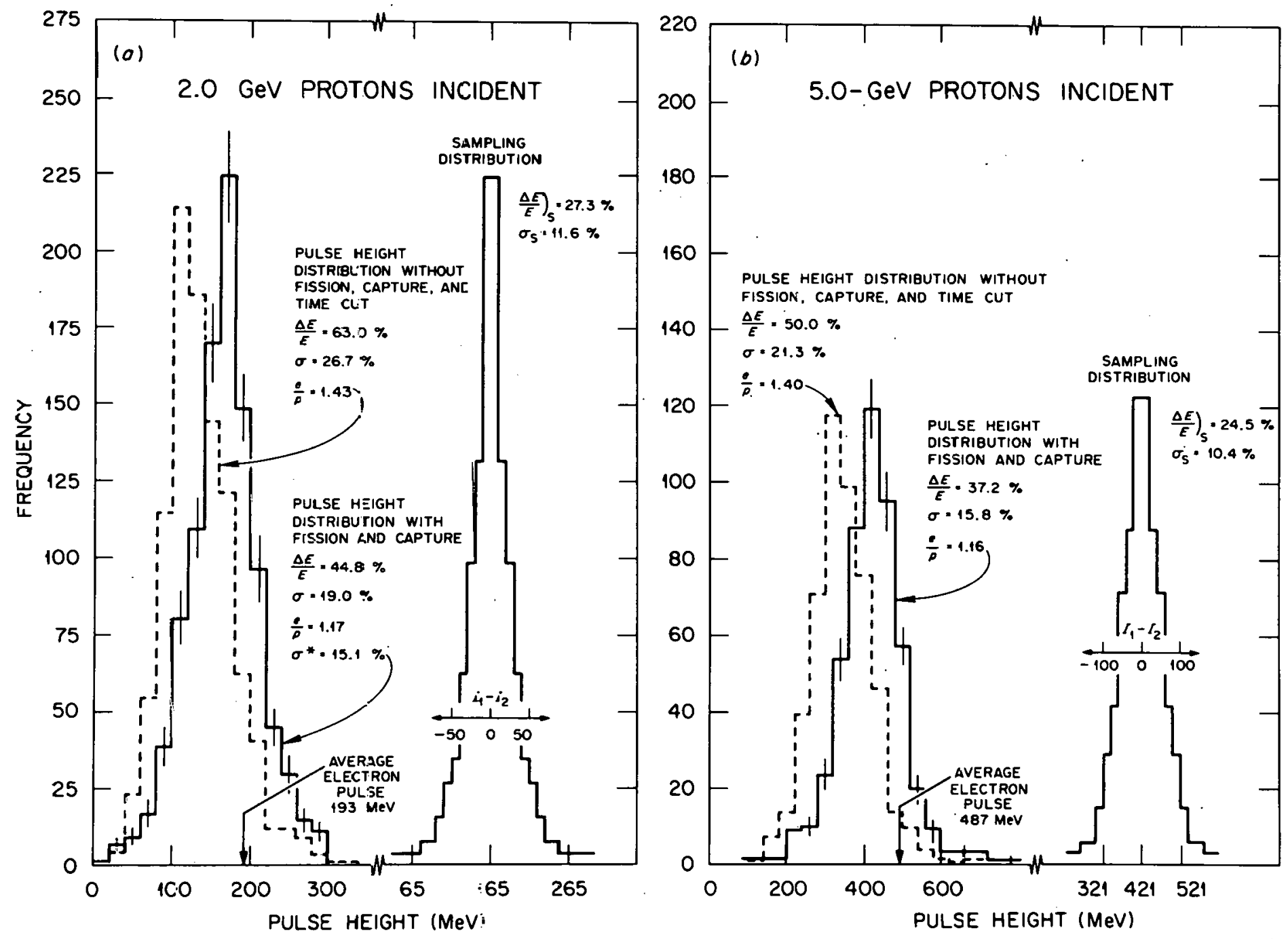

Fig. 6. Pulse Height and Sampling Distributions Expected from a U-Fe-A Calorimeter When 2- arid 5-GeV Protons are Incident. 
U-Fe-A CALORIMETER

NO RESTRICTIONS ON INITIAL INTERACTION 50 nsec. TIME CUT
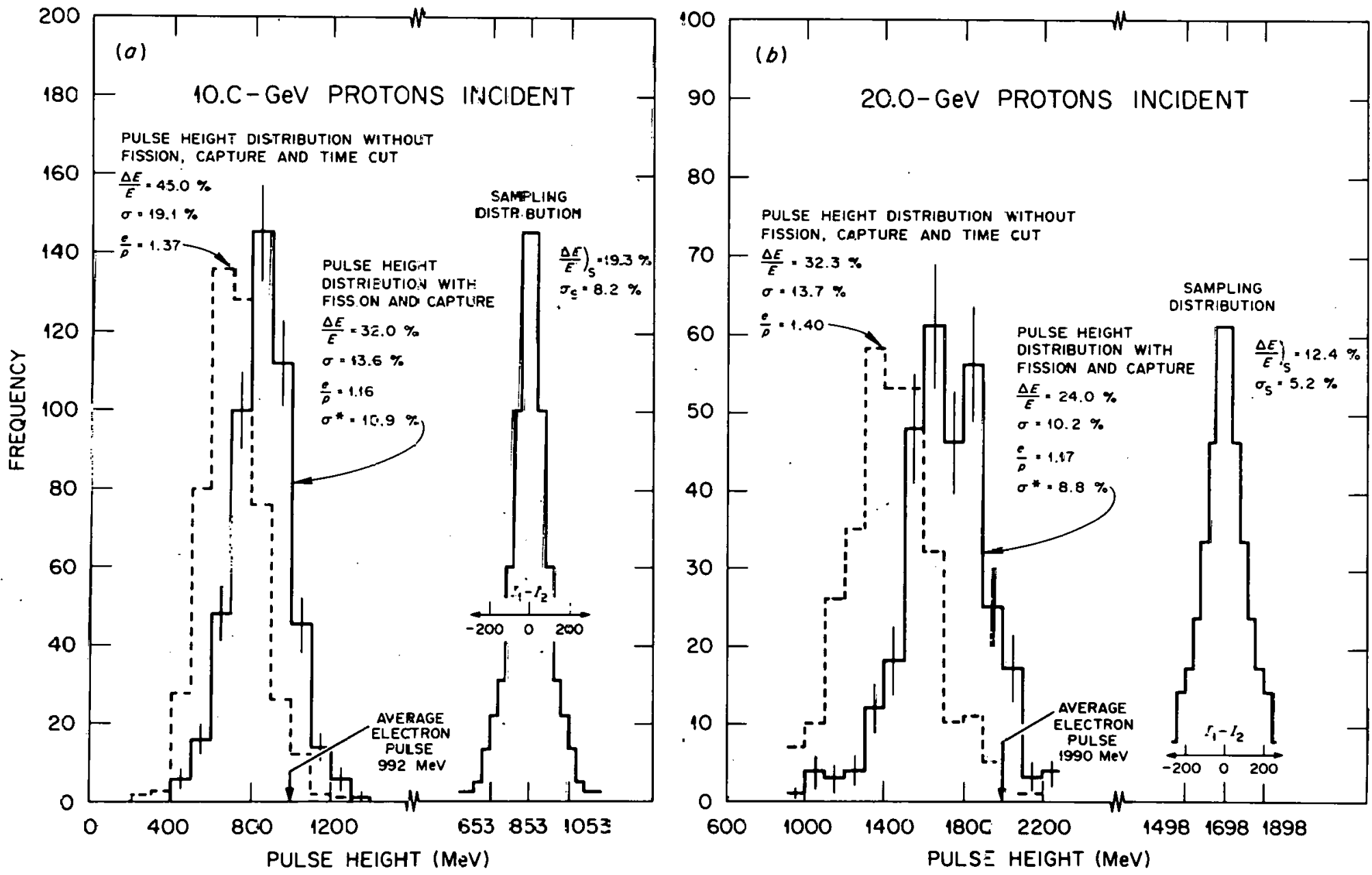

Fig. 7. Fulse Height and Sampling Distributions Expected from a U-Fe-A Calorimeter When 5 - and $10-\mathrm{GeV}$ Protons are Incident. 
ORNL-DWG 77-2974

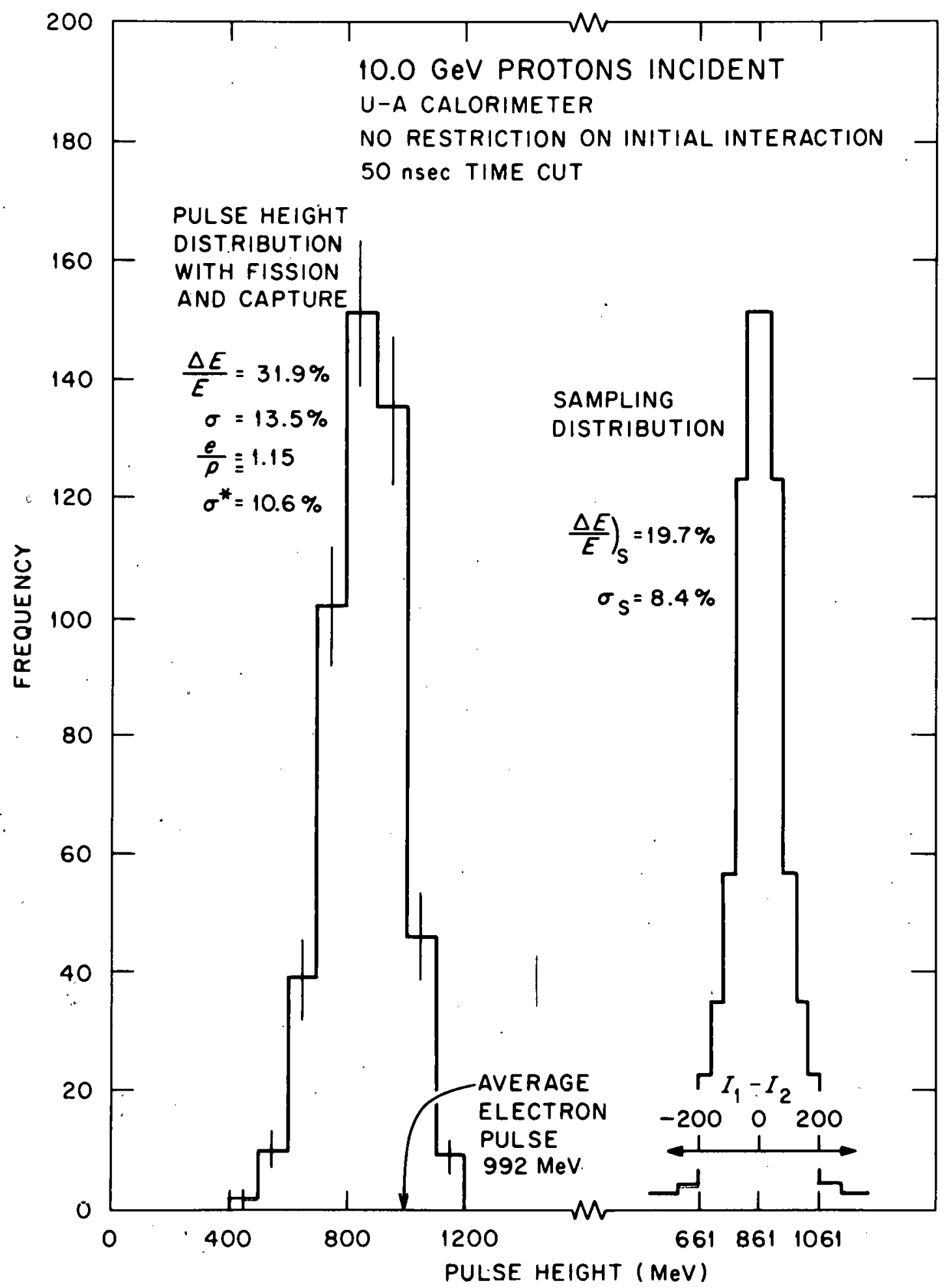

Fig. 8. Pulse Height and Sampling Distributions Expected from a U-A Calorimeter When 10-GeV Protons are Incident. 

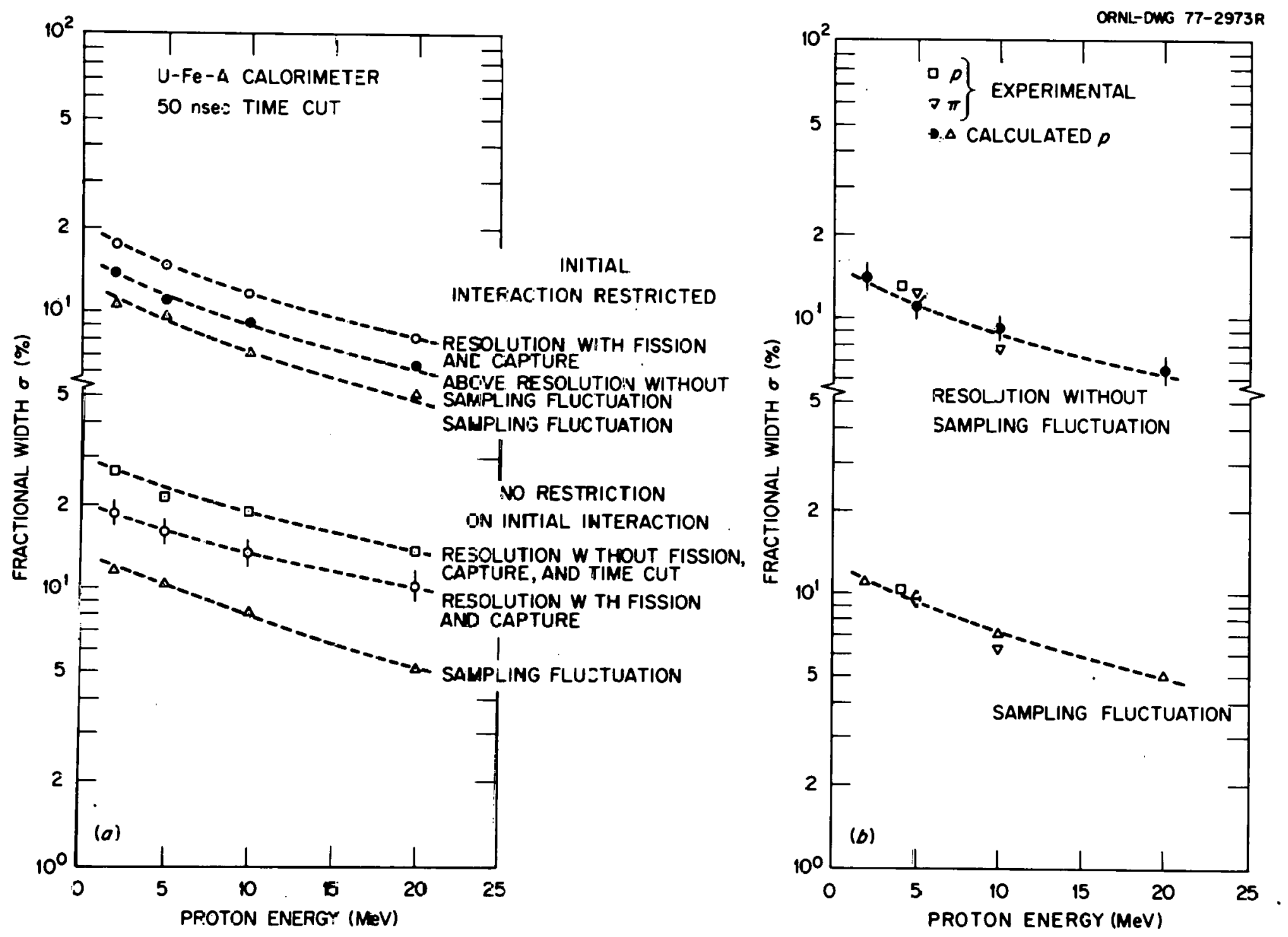

Fig. 9. The Resolution of the U-Fe-A Calorimeter as a Function of Proton Energy. 


$$
\left.\begin{array}{l}
x \\
+\quad \text { PROTONS }
\end{array}\right\} \text { EXPERIMENTAL }
$$

CALCULATED WITH PROTONS INCIDENT

$$
\text { U-Fe-A CALORIMETER }
$$

\section{FISSION AND $50 \mathrm{nsec}$

$\frac{\text { CAPTURE }}{\text { YES NO TIME CUT }} \frac{\text { RESTRICTED COLLISION SITE }}{\text { YES NO }}$
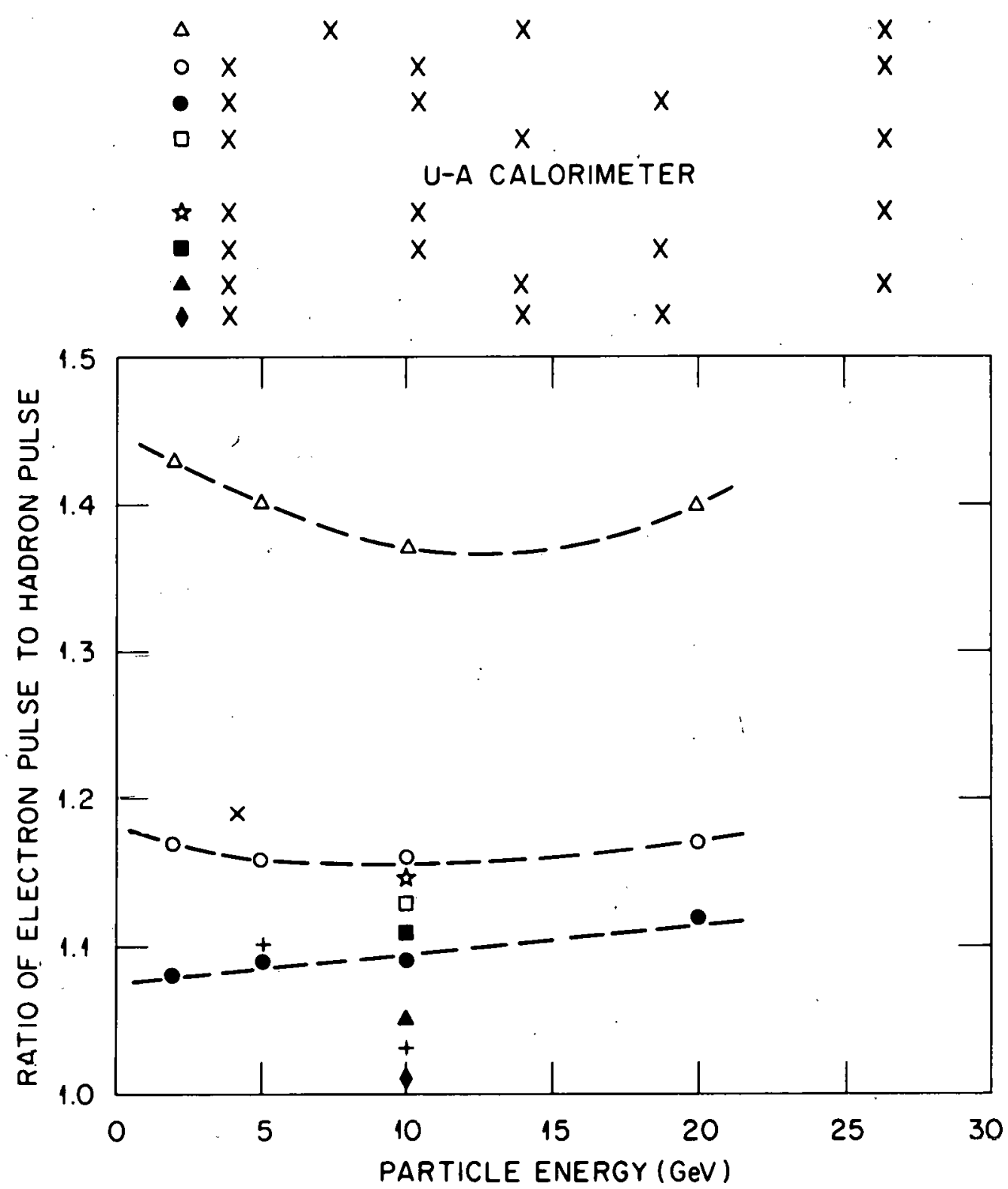

Fig. 10. The Ratio of the Average Electronic Energy Deposition to the Average Hadronic Energy Deposition as a Function of Particle Energy. 
This increase is due to increased leakage. The increase that results for the restriction collision data is due primarily to the fact that more than $50-n s e c$ collection time is needed. It is quite obvious from the figure that a rather wide spread in $e / p$ ratios can be obtained depending upon the calorimeter and the constraint. The important aspect of this figure is, however, that the e/p ratio can be reduced substantialiy. The experimental data has been modified to account for a total U-A system.

The individual contributors to the energy deposition have each been boxed separately in Fig. 11 for 2- and 10-GeV protons incident on the $\mathrm{U}-\mathrm{Fe}-\mathrm{A}$ calorimeter. If the calorimeter was only sensitive to secondary protons then the pulse height distribution would be represented by the dashed curves in the figure. It is obvious from the figure that the fluctuations are dominated by correlations between the produced protons, low-energy neutrons and $\pi^{\circ}$ 's (primarily at $10 \mathrm{GeV}$ ).

The laterally integrated spatial energy deposition for incident 2-, 5-, 10-, and 20-GeV protons is given in $F i g .12$ for the $U-F=-A$ calorimeter.

\section{Cunclusions}

The use of uranium in calorimeter application to reduce the "rluclear fluctuations" appears very promising. A factor of $\sim$ two improvement in the resolutions appears possible. However, since the sampling fluctuations are in uranium-loaded calorimeters a larger contributor to the total resolution, their thickness must remain small or the benefits from using uranium will be greatly reduced. In large calorimeters where there is small leakage of low-energy neutrons, pileup effects may occur if the incident particle current is large ( $\left.210^{5}-10^{6} / \mathrm{sec}\right)$. 
NO RESTRICTION ON INITIAL INTERACTION

ORNL-OWG 77-2971

50 nsec TIME CUT

II-Fo-A CALORIMLTLR
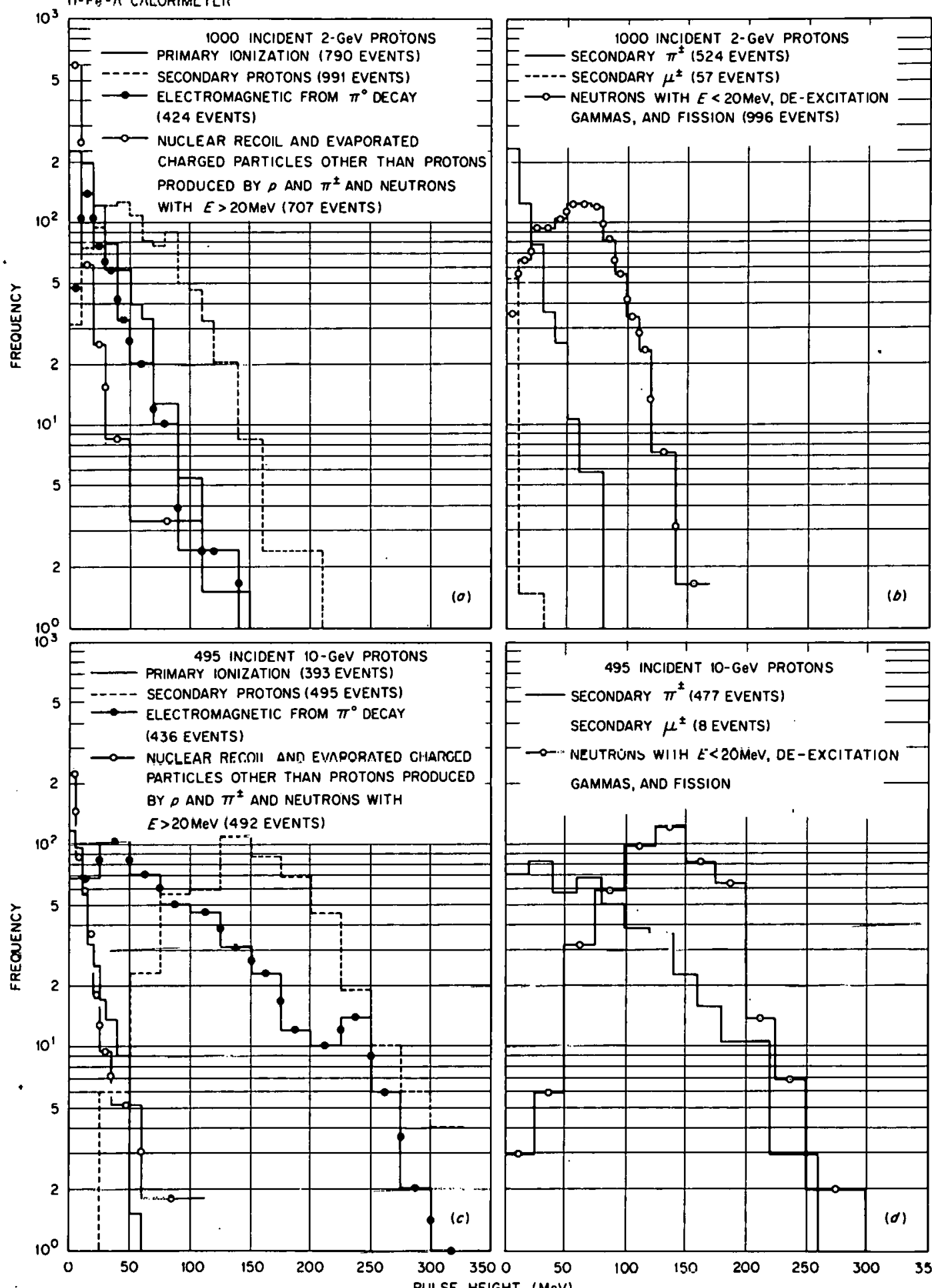
GAMMAS, AND FISSION
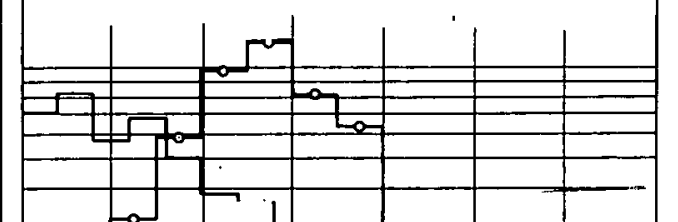

Fig. 11. Fluctuations in the Individual Contributors to the Total Pulse Height Distributions from 2- and 10-GeV Incident Protons on the U-Fe-A Calorimeter. 


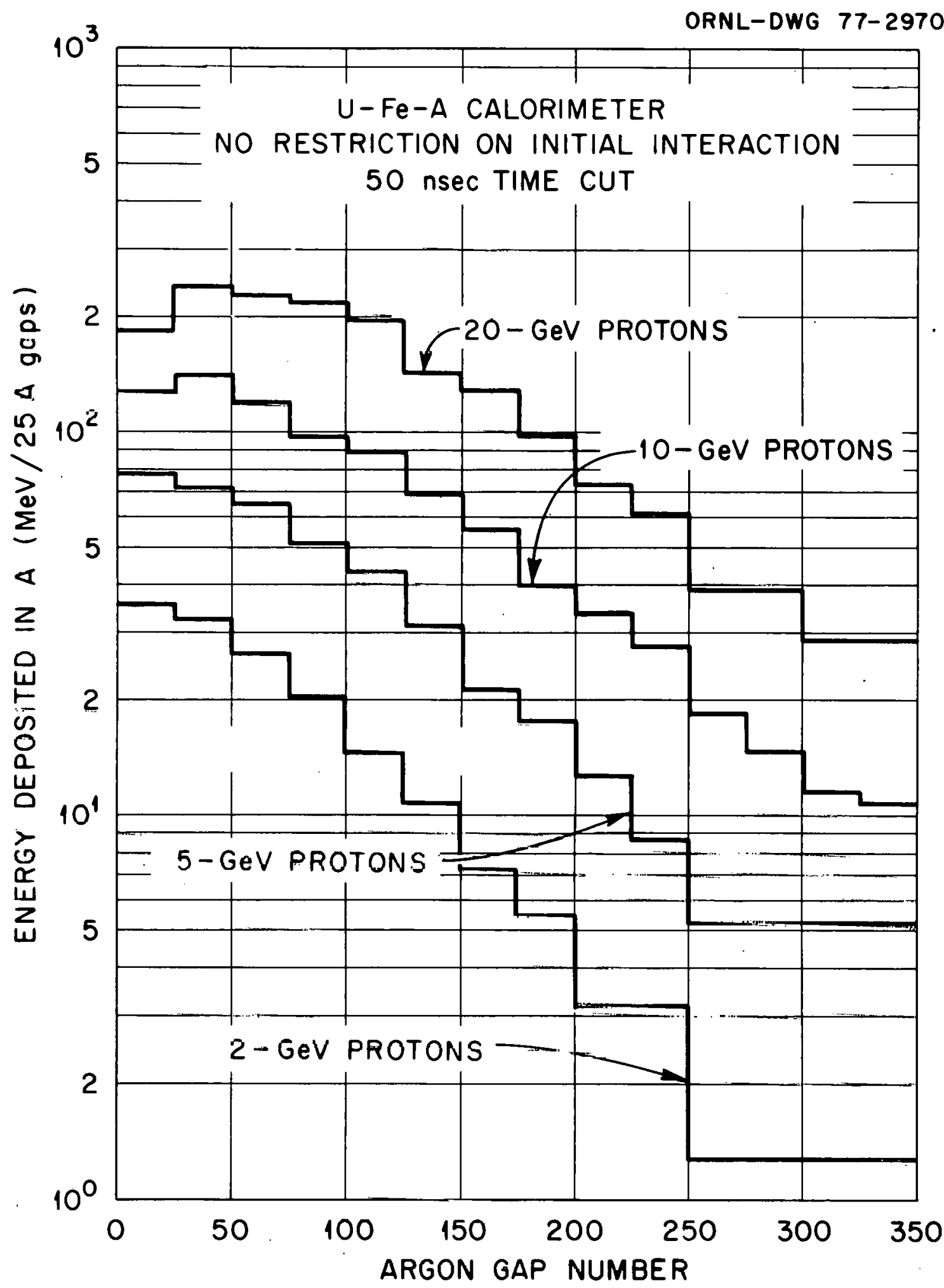

Fig. 12. Spatial Dependence of the Hadron-Induced Cascade in the U-Fe-A Calorimeter. 


\section{References}

1. C. W. Fabjan et az., Phys. Letters 60B, 105 (1975).

2. C. W. Fabjan et al., Nucl. Instr. Meth. 141, 61 (1977).

3. T. A Gabriel et al., Nucl. Instr. Meth. 129, 409 (1975).

4. R. L. Hahn and H. W. Bertini, Phys. Rev. $\underline{\text { C6}}$, No. 2, 660 (1972).

5. ENDFB/IV, Neutron Cross Section Center, Brookhaven National Laboratory, Upton, NY.

6. H. W. Bertini, Phys. Rev. 131, 1801 (1963).

7. E. A. Staker et al., "The MפRSE Code-A-Multigroup Neutron and Gamma-Ray Monte Carlo Transport Code," ORNL/TM-4585, Oak Ridge National Laboratory (1970).

8. N. M. Greene et al., "AMPX" A Modular Code System for Generating Coupled Multigroup Neutron-Gamma Libraries from ENDF/B," ORNL/TM-3706, Oak Ridge National Laboratory (1973).

9. K. C. Chandler and T. W. Armstrong, "Operating Instructions for the High-Energy Nucleon Meson Transport Code HETC," ORNL/TM-4744, Oak Ridge National Laboratory. (1972).

10. T. A. Gabriel and J. D. Amburgey, "CALøR: A Monte Carlo Program Package for the Design and Analysis of Calorimeter Systems," ORNL/TM-5619, Oak Ridge National Laboratory (1977).

11. W. Hofmann et al., Nucl. Instr. Meth. 135, 151 (1976). 
THIS PAGE

WAS INTENTIONALLY

LEFT BLANK 
Internal Distribution

ORNL/TM-5769

1-2. L. S. Abbott

3. F. S. Alsmiller

4. R. G. Alsmiller, Jr.

5. H. W. Bertini

6-20. T. A. Gabriel

21. F. C. Maienschein

22. F. R. Mynatt

23. E. M. Oblow

24. R. W. Rouss in

25. RSIC

26. R. T. Santoro

27. M. L. Tobias
28. C. R. Weisbin

29. G. E. Whitesides

30. A. Zucker

31. P. Greebler (Consultant)

32. W. W. Havens, Jr. (Consultant)

33. A. F. Henry (Consultant)

34. R. E. Hurig (Consultant)

35-36. Central Research Library

37. ORNL Y-12 Technical Library Document Reference Section

38. Laboratory Records Department

39. Laboratory Records, ORNL R.C.

40. ORNL Patent Office

\section{External Distribution}

41. H. Goldstein, Columbia University, 287A Mudd Building, New York, NY $1002 \%$.

42-68. Technical Information Center (TIC).

69. U.S. ERDA Oak Ridge Operations, Research and Technical Support Division, P. 0. Box E, Oak Ridge, TN 37830: Director.

70-118. Given High-Energy Accelerator Shielding distribution. 